\section{A broader perspective needed in Canadian guideline for Parkinson disease}

Thank you for the making available the "Canadian Guideline for Parkinson Disease"1 with its extensive documentation of expertise and ethical rigour. For the past 12 years, since co-founding Parkinson en mouvement (www.parkinsonenmouvement.org), I and my colleagues have built up years of observation in our work with patients with Parkinson Disease using various movement-based therapies.

We were surprised to read as one of the key points that new therapies such as deep brain stimulation and intrajejunal levodopa-carbidopa gel infusion are now "routinely" used in Parkinson disease to manage motor symptoms. Our impression is that these expensive treatments are as yet far from routine. They appear to be available to a highly selected category of patients, at high cost, with the need for specialized technical follow-up for the rest of their lives. There are also many potential adverse effects to these new treatments.

On the other hand, we strongly agree when the guideline asserts - as another key point - that evidence exists to support early institution of exercise at the time of diagnosis, in addition to the clear benefit in those with well-established disease. However, under the treatment section of the guideline, we would have added additional movement-based therapies for which there is solid research evidence in addition to the 2 studies of physiotherapy and occupational therapy that were referenced in the guideline. ${ }^{2-15}$ Moreover, there is a group dimension to the treatments we and others offer that can mitigate isolation and loneliness, which no doubt contribute to the risk of apathy as a barrier to patient adherence mentioned by the authors of the guideline ("Continued therapy is required to sustain benefits, and this is particularly important in Parkinson disease as apathy is a barrier to patient adherence in the absence of scheduled lessons or training"). ${ }^{1}$

Given the concern expressed in the guideline about the limited resources currently available for care of patients with Parkinson disease, the rehabilitation section could have been strengthened. This section is lost in the 2.5 pages of detailed accounting of the evidence for various pharmacologic options. Because a range of movement-based therapies (e.g., physio exercises, dance, dance/movement therapy and LSVT Big and Loud [intensive, effective, one-on-one treatments created to help people with Parkinson disease address walking, balance and other activities of daily living]) are widely available at low cost and with few adverse effects, it would be better to highlight these interventions as first-line treatments.

The visual summary can be seen as quite misleading and potentially discouraging. If read alone, it appears to focus on negative and often misunderstood aspects of Parkinson disease. The ending statement in the Diagnosis and Progression section, "No therapies are effective for slowing or stopping brain degeneration in Parkinson disease," may leave readers with a sense of hopelessness. I question this statement having such a prominent place.

The panel of experts taking part in the development of the guideline is impressive. But it would be valuable to have included nonmedical practitioners, movement-based therapists and patients.

Thank you again for this important collaborative update on Parkinson disease.

\section{Joanabbey Sack MA BC-DMT RDT}

Educator, dance/movement therapist, Concordia University; Parkinson en mouvement, Montréal, Que.

- Cite as: CMAJ 2020 March 16;192:E289. doi: $10.1503 / \mathrm{cmaj} .74537$

\section{References}

1. Grimes D, Fitzpatrick M, Gordon J, et al. Canadian guideline for Parkinson disease. CMAJ 2019;191:E989-1004.

2. Batson G, Migliarese $\mathrm{SJ}$, Soriano $\mathrm{CH}$, et al. Effects of improvisational dance on balance in Parkinson's disease: a two-phase fMRI case study. Phys Occup Ther Geriatr 2014;32:188-97.

3. Batson G. Feasibility of an intensive trial of modern dance for adults with Parkinson disease. Complement Health Pract Rev 2010;15:65-83.

4. Chaudhary S, Joshi D, Pathak A, et al. Comparison of cognitive profile in young- and late-onset Parkinson's disease patients. Ann Indian Acad Neurol 2018;21:130-2.

5. Duncan RP, Earhart GM. Randomized controlled trial of community-based dancing to modify disease progression in Parkinson's disease. Neurorehabil Neural Repair 2012;26:132-43.

6. Earhart GM. Dance as therapy for individuals with Parkinson disease. Eur J Phys Rehabil Med 2009;45:231-8.

7. Farley BG, Fox CM, Ramig LO, et al. Intensive amplitude-specific therapeutic approaches for Parkinson disease: toward a neuroplasticityprincipled rehabilitation model. Top Geriatr Rehabil 2008;24:99-114.

8. Foster ER, Golden L, Duncan RP, et al. Community-based Argentine tango dance program is associated with increased activity participation among individuals with Parkinson's disease. Arch Phys Med Rehabil 2013;94:240-9.

9. Goodwin VA, Richards SH, Taylor RS, et al. The effectiveness of exercise interventions for people with Parkinson's disease: a systematic review and meta-analysis. Mov Disord 2008;23:631-40.

10. Hackney ME, Earhart GM. Effects of dance on movement control in Parkinson's disease: a comparison of Argentine tango and American ballroom. J Rehabil Med 2009;41:475-81.

11. Homann KB. Embodied concepts of neurobiology in dance/movement therapy practice. $A m \mathrm{~J}$ Dance Ther 2010;32:80-99.

12. Kalyani HHN, Sullivan KA, Moyle G, et al. Impacts of dance on cognition, psychological symptoms and quality of life in Parkinson's disease. NeuroRehabilitation 2019;45:273-83.

13. Mendrek A. From depression to Parkinson's disease: the healing power of dance. Toronto: The Conversation Canada; 2019 Dec. 4. Available: https://theconversation.com/from-depression-to -parkinsons-disease-the-healing-power-of-dance -123748 (accessed on 2020 Jan. 6).

14. Prewitt CM, Charpentier JC, Brosky JA, et al. Effects of dance classes on cognition, depression, and self-efficacy in Parkinson's disease. Am J Dance Ther 2017;39:126-41.

15. Stevens C, McKechnie S. Thinking in action: thought made visible in contemporary dance. Cogn Process 2005;6:243-52.

Competing interests: None declared. 